\title{
PENGETAHUAN PERSONAL HYGIENE BERHUBUNGAN DENGAN TIMBULNYA GEJALA PENYAKIT KULIT PADA PETUGAS PENGANGKUT SAMPAH
}

\author{
Putu Firda Ika Nahrajanti ${ }^{1}$, I Wayan Sudiadnyana ${ }^{2}$
}

Abstract Knowledge of personal hygiene is very important to note by the garbage collector to maintain their life, health and welfare in prevent symptoms of skin diseases. This research to find out the knowledge of the personal hygiene with the symptoms of a skin disease in the garbage collector. This type research is analytic survey on the interview with the cross sectional.The sample as many as 70 officers garbage, located in the Badung Regency. Data were collected by using a questionnaire and statistical analysis by using the Chi Square test. The result from the garbage collector knowledge are about 12,9\% have a good knowledge, about $32,8 \%$ have an averange knowledge and about 54,3\% have a bad knowledge. Respondents with some symptoms as much as 58,6\% and some who were not as symptoms is as much as $41.1 \%$. Symptoms of skin disease most often happen by the garbage collector were itchy, red stain, redness of the skin, bumps, scaly skin, and peeling skin. Chi Square statistical results $P$ value $=0,000<a(0.05)$, which means there is a significant relationship between the level of knowledge about personal hygiene with the onset of symptoms of skin diseases in the garbage collector with a moderate level of relationship $(C C$ value $=0.537)$. The garbage collector should further enhance his knowledge of personal hygiene by given counseling.

Keywords: Knowledge, Personal Hygiene, Symptoms of Skin Disease

\section{PENDAHULUAN}

Sampah atau waste diartikan sebagai suatu yang tidak digunakan, tidak terpakai, tidak disenangi atau sesuatu yang dibuang ${ }^{1}$. Petugas pengangkut sampah seringkali mengalami cedera akibat sampah yang ditanganinya pada saat melaksanakan tugasnya ${ }^{2}$. Resiko sebagai petugas pengangkut sampah sangat besar karena sampah mengandung banyak sekali bakteribakteri patogen ${ }^{3}$. Salah satu penyakit yang dialami oleh petugas pengangkut sampah adalah gejala penyakit kulit. Selain itu 
pemeliharaan personal hygiene (kebersihan diri) sangat diperlukan untuk kenyamanan individu, keamanan, kesehatan dan psikis seseorang. Personal hygiene meliputi kebersihan kulit, kebersihan rambut, kebersihan gigi, kebersihan mata, kebersihan telinga, dan kebersihan tangan, kaki, dan kuku. Kebersihan kulit merupakan faktor utama yang dapat menimbulkan penyakit kulit ${ }^{4}$. Berdasarkan hasil observasi awal yang dilakukan saat wawancara kepada pihak DLHK Kabupaten Badung mengatakan bahwa para petugas pengakut sampah ada beberapa orang yang mengalami gejala penyakit kulit. Demikian pula hasil observasi awal pada 30 petugas pengangkut sampah yang dilakukan di lapangan, ditemukan $90 \%$ yang mengalami gejala penyakit kulit, dengan gejala berupa gatal-gatal, kudis (skabies). Namun, hal ini tidak begitu dihiraukan oleh para pekerja petugas pengangkut sampah.

Tujuan $\begin{array}{lr}\text { penelitian } \\ \text { untuk } \\ \text { mengetahui } \\ \text { hubungan }\end{array}$ tingkat
pengetahuan tentang personal
hygiene dengan timbulnya gejala
penyakit kulit pada petugas
pengangkut sampah di TPST di
wilayah Kabupaten Badung tahun
2020.
2020.

\section{METODE PENELITIAN}

Jenis penelitian yang digunakan adalah survei analitik dengan metode wawancara dengan pendekatan Cross Sectional $^{5}$ yaitu menganalisa antara variabel bebas berupa tingkat pengetahuan personal hygiene dengan variabel terikat yaitu gejala penyakit kulit. Populasi 219 dengan sampel yang diambil sebanyak 70 sampel petugas pengangkut sampah. Teknik pengambilan sampel menggunakan teknik simpel random sampling ${ }^{5}$. Teknik pengumpulan data menggunakan kuesioner serta wawancara dengan pihak terkait. Pada penelitian ini menggunakan uji analitik chi square dengan kemaknaan $p<0,05$. serta dilakukan perhitungan $C C$ untuk mengetahui keeratan hubungan antara dua variabel ${ }^{6}$.

\section{HASIL DAN PEMBAHASAN}

\section{A. Tingkat Pengetahuan Personal Hygiene}

Hasil penelitian terhadap tingkat pengetahuan petugas pengangkut sampah diperoleh hasil tingkat pengetahuan baik sebanyak 12,9\%, sedang sebanyak $32,8 \%$ dan buruk sebanyak 54,3\%. Responden dengan timbul gejala penyakit kulit sebanyak $58,6 \%$ dan tidak timbul gejala penyakit kulit sebanyak $41,1 \%$. Hal ini 
menunjukan bahwa petugas pengangkut sampah dominan memiliki tingkat pengetahuan personal hygiene yang buruk.

Penyampaian informasi tentang personal hygiene dapat dilakukan salah satunya dengan metode penyuluhan dari puskesmas, pihak DLHK Kabupaten Badung ataupun dengan pemasangan spanduk atau poster di masing-masing TPST. Menurut Pratama \& Prasasti (2017), pengetahuan dan motivasi, akan mempengaruhi praktek hygiene seseorang. Sedangkan motivasi merupakan kunci penting dalam pelaksanaan hygiene tersebut. Permasalahan yang sering terjadi adalah ketiadaan motivasi karena kurangnya pengetahuan ${ }^{7}$.

Selain itu Menurut Sajida (2012), semakin bertambah umur seseorang maka akan mempengaruhi kemampuan berfikir, baik dalam menerima atau menangkap informasi yang diberikan orang lain ${ }^{8}$. Menurut Azizah (2019), Tingkat pendidikan masyarakat yang rendah mengakibatkan rendahnya kepedulian terhadap pencegahan penyakit. Pendidikan dapat membawa wawasan atau pengetahuan seseorang, selain itu tingkat pendidikan juga menentukan pengetahuan terhadap sesuatu hal khususnya pengetahuan kebersihan lingkungan yang berdampak pada status kesehatan ${ }^{9}$.

\section{B. Gejala penyakit kulit pada petugas pengangkut sampah}

Responden dengan timbul gejala penyakit kulit sebanyak 58,6\% dan tidak timbul gejala penyakit kulit sebanyak $41,1 \%$. Gejala peyakit kulit yang paling sering dialami oleh petugas pengangkut sampah adalah gatal-gatal, bercak merah, kemerahan pada kulit, bentol-bentol, kulit bersisik, dan kulit mengelupas.

Gejala penyakit kulit yang dialami oleh petugas pengangkut sampah TPST di wilayah Kabupaten Badung merupakan penyakit akibat kerja dimana hasil pantauan di lapangan ditemukan rata-rata petugas pengangkut sampah tidak menggunakan alat perlindungan diri yang lengkap dengan alasan merasa terganggu atau kurang nyaman saat bekerja mengangkut sampah. Menurut Fitria (2017), salah satu penyebab gangguan kulit yaitu pekerjaan dan kebersihan perorangan yang baik. Untuk memelihara kebersihan kulit kebiasaan - kebiasaan yang sehat harus selalu diperhatikan seperti menjaga kebersihan pakaian, mandi secara teratur, mandi menggunakan air bersih yang mengalir dan sabun, menggunakan barang - barang 
keperluan sehari - hari milik sendiri, makan yang bergizi terutama banyak makan sayur dan buah, dan menjaga kebersihan lingkungan ${ }^{10}$ Selain itu menurut Srisantyorini \& Cahyaningsih (2017), Penyakit kulit dapat diderita oleh semua orang dari golongan umur tetapi kulit manusia mengalami degenerasi seiring bertambahnya usia, seorang yang memiliki usia lebih tua memiliki kulit kering dan tipis yang tidak toleran terhadap sabun dan pelarut ${ }^{11}$.

\section{Hubungan \\ pengetahuan \\ tingkat \\ personal hygiene dengan \\ timbulnya gejala penyakit \\ kulit pada petugas \\ pengangkut sampah}

Hasil penelitian yang dilakukan pada petugas pengangkut sampah TPST di wilayah Kabupaten Badung diperoleh hasil responden yang pengetahuannya baik namun mengalami gejala timbul penyakit kulit sebanyak 1 orang $(11,1 \%)$ sedangkan yang mengalami tidak timbul gejala penyakit kulit sebanyak 8 orang $(88,9 \%)$. Responden dengan pengetahuan sedang namun mengalami timbul gejala penyakit kulit sebanyak 7 orang $(30,4 \%)$ sedangkan yang mengalami tidak timbul gejala penyakit kulit sebanyak 16 orang $(69,6 \%)$. Responden dengan pengetahuan buruk namun mengalami timbul gejala penyakit kulit sebanyak 33 orang $(86,8 \%)$ dan yang mengalami tidak timbul gejala penyakit kulit sebanyak 5 orang $(13,2 \%)$. hasil uji statistik Chi Square memperoleh nilai $\mathrm{p}=0,000<\mathrm{a}(0,05)$, yang berati Ho ditolak dan $\mathrm{Ha}$ diterima yang berati terdapat hubungan signifikan antara tingkat pengetahuan mengenai personal hygiene dengan timbulnya gejala penyakit kulit pada petugas pengangkut sampah dengan tingkat hubungan yang sedang, dengan nilai yang diperoleh $\mathrm{CC}=0,537$.

Tindakan petugas pengangkut sampah untuk menjaga kesehatan diri dan terhindar dari gejala penyakit kulit adalah dengan meningkatkan pengetahuan, pemahaman dan aplikasi yang baik mengenai personal hygiene seperti; menjaga kebersihan kulit, kebersihan rambut, dan kebersihan tangan, kaki, kuku, merawat pakaian kerja dan menggunakan APD yang lengkap. Selain itu masing-masing TPST di wilayah Kabupaten Badung selalu menyiapkan APD yang lengkap dan memasang spanduk atau poster tentang personal hygiene agar petugas bisa langsung menerapkannya.

\section{SIMPULAN}

Berdasarkan hasil penelitian dan pembahasan dapat disimpulkan tingkat pengetahuan petugas pengangkut sampah yang baik sebanyak 12,9\%, sedang sebanyak $32,8 \%$, dan buruk sebanyak $54,3 \%$. Selain itu yang mengalami gejala penyakit kulit sebanyak $58,6 \%$ dan yang 
mengalami tidak timbul gejala penyakit kulit sebanyak 41,4\%. Hasil uji statistik ada hubungan yang signifikan antara tingkat pengetahuan mengenai personal hygiene dengan timbul gejala penyakit kulit.

\section{SARAN}

Upaya yang dapat dilakukan untuk meningkatkan pengetahuan, pemahaman dan aplikasi yang baik mengenai personal hygiene seperti; menjaga kebersihan kulit, kebersihan rambut, dan kebersihan tangan, kaki, kuku, merawat pakaian kerja dan menggunakan APD yang lengkap. Selain itu masing-masing TPST di wilayah Kabupaten Badung selalu menyiapkan APD yang lengkap dan memasang spanduk atau poster tentang personal hygiene agar petugas bisa langsung menerapkannya.

\section{DAFTAR PUSTAKA}

1. Sumantri, A. Kesehatan Lingkungan. (Kencana, 2015).

2. Nasir, D. Hubungan Hygiene Perorangan , Penggunaan Alat Pelindung Diri, Lingkungan Kerja Dan Status Gizi Dengan Kejadian Diare Pada Petugas Pengangkut Sampah Dinas Kebersihan Dan Keindahan Kota Banda Aceh Tahun 2017. (2018).

3. Tryanto, E. Aplikasi Konsep At Risk Pada Populasi Pemulung Sampah. (2009).

4. Duwita, S. Hubungan Personal Hygiene
Dengan Penyakit Kecacingan Pada

Petugas Pengangkut Sampah Kecamatan

Salak Kabupaten Pakpak Bharat Tahun 2018. (2018).

5. Notoatmodjo, S. Metode Penelitian Kesehatan. (Pt. Rineka Cipta, 2012).

6. Sugiyono. Metode Penelitian Kuantitatif, Kualitatif Dan $R \& D$. (Cv Alfabeta, 2013).

7. Pratama, K. F. \& Prasasti, C. I. Disease Leather Of Scavenger In Kenep Tpa Reviewed From Safety Aspects And Health Work. 135-145 (2017). Doi:10.20473/Jjosh.V6i2.2017.135-145.

8. Sajida, A. Hubungan Personal Hygiene Dan Sanitasi Lingkungan Dengan Keluhan Penyakit Kulit Di Kelurahan Denai Kecamatan Medan Denai Kota Medan Tahun 2012. (2012).

9. Azizah, F. N. Hubungan Higiene Perorangan Dan Penggunaan Alat Pelindung Diri Dengan Gangguan Kulit Pada Petugas Pengangkut Sampah Kota Tangerang Selatan Tahun 2018 Individual Hygiene Relationship And Use Of Personal Protective Equipment With Skin Disorders In The South. J. Ilm. Kesehat. Masy. 11, 126-140 (2019).

10. Fitria, M. Hubungan Higiene Perorangan Dan Karakteristik Pemulung Dengan Keluhan Gangguan Kulit Di Tpa Tandukan Raga Kecamatan Stm Hilir Kabupaten Deli Serdang Tahun 2017. (2017).

11. Srisantyorini, T. \& Cahyaningsih, N. F. Analisis Kejadian Penyakit Kulit Pada Pemulung Di Tempat Pengolahan 
Jurnal Kesehatan Lingkungan Vol.10 No.2 Oktober 2020: 126-131

Sampah Terpadu ( Tpst ) Kelurahan

Sumur Batu Kecamatan Bantar Gebang

Kota Bekasi. 135-147 (2017). 